\title{
PERBANDINGAN PERFORMANSI KOLEKTOR SURYA TIPE EVACUATED TUBE MENGGUNAKAN FLUIDA KERJA ETANOL DENGAN TIPE PELAT DATAR
}

\author{
Rusmana ${ }^{1}$, Kurnia Chandra ${ }^{2}$ \\ Jurusan Teknik Konversi Energi Politeknik Negeri Bandung \\ e-mail: kurniachandra21@yahoo.co.id
}

ABSTRAK

Mengingat wilayah Indonesia yang letaknya berada di garis khatulistiwa, sumber energi surya yang diterima Indonesia sangat melimpah. Pemanfaatan yang paling sederhana adalah menjadikan energi surya sebagai sumber panas pada proses pemanasan air. Teknologi kolektor surya merupakan salah satu sarana untuk mengambil panas matahari. Aneka jenis kolektor surya memiliki kinerja yang bervariasi. Kemampuan penyerapan panas yang tinggi dapat diperoleh dari kolektor surya berjenis evacuated tube collector yang mempunyai waktu pemanasan air awal lebih cepat dibandingkan dengan jenis flat plate collector. Penelitian ini bertujuan untuk mengetahui perbandingan efisiensi kolektor surya tabung vakum terhadap solar water heater sederhana. Metode pengujian dilakukan dengan cara memasukan debit air yang sama pada setiap pengujian. Hasil pengujian menunjukan bahwa solar water heater tabung vakum dengan fluida kerja etanol memberikan efisiensi tertinggi sebesar $44.5 \%$ dan efisiensi terendah sebesar $26.4 \%$. Temperatur air output tertinggi mencapai $35.4^{\circ} \mathrm{C}$.

Kata kunci : pemanas air, radiasi matahari, tabung vakum, kolektor surya

\section{ABSTRACT}

As Indonesia located in the equator line, solar energy is one of the abundant source to be cultivated. The simplest exploitation is water heater. Solar collector is one of technologies to gain heat from the sun. Various kinds of solar collector gives various performances. The ability to absorb heat gained by evacuated tube collector that has faster pre-warming time of water than that kind of flat plate collector. This experiment is conducted to explore the comparison of evacuated tube collector than simple solar water heater. The methods to test its performance is conducted by flowing the same amount of water debit on each test. The highest efficiency of vacuum (evacuated) tube solar water heater using ethanol is $44.5 \%$ and the lowest is $26.4 \%$. The highest temperature of solar collector water output was $35.4^{\circ} \mathrm{C}$.

Keywords : solar, radiation, vacuum tube, solar collector, evacuated tube collector.

\section{PENDAHULUAN}

Salah satu sumber energi yang melimpah di Indonesia adalah energi surya (matahari) karena letak Indonesia yang berada di garis Khatulistiwa, jalur yang menerima sinar matahari sepanjang tahun. Potensi sumber energi yang besar ini seharusnya dapat dioptimalkan dengan baik.

Pemanfaatan sederhana dari energi matahari adalah dijadikan sebagai sumber energi pada pemanas air tenaga surya. Salah satu teknologi untuk pemanfaatan energi matahari yang cukup baik yaitu kolektor surya.

Terdapat macam-macam tipe dari kolektor surya. Salah satu tipe kolektor surya yang paling sering digunakan adalah kolektor surya pelat datar. Untuk lebih mengoptimalkan pemanfaatan panas, 
diperlukan suatu inovasi dari jenis kolektor surya, yaitu tipe evacuated tube collector.

Kolektor surya tipe ini dibuat dengan jenis pipa tembaga yang diisi dengan fluida etanol yang berfungsi sebagai penghantar panas dari sisi evaporator hingga ke sisi kondensor. Ketika kolektor ini diberi panas maka fluida etanol ini akan menguap dari sisi evaporator hingga mengalir ke sisi kondensor. Sisi kondensor ini dihubungkan dengan pipa tembaga berisi fluida air yang mengalir melintang melewati pipa tembaga berisi etanol. Pipa tembaga etanol ini mempunyai diameter yang lebih kecil dibandingkan dengan pipa dengan fluida air. Pipa dengan fluida air ini dialirkan melintang melewati pipa tembaga etanol agar terjadi perpindahan panas antara fluida air dengan pipa tembaga etanol tersebut. Kolektor surya jenis ini memakai jenis kaca tabung silinder yang difungsikan sebagai penutup dari kolektor surya.

Kolektor surya terdiri dari pelat penyerap yang memiliki konduktivitas termal yang baik, dimana pelat penyerap (absorber) berhubungan dengan kolektor. Kemudian terdapat kaca penutup transparan berbentuk tabung silinder serta sebuah isolator di bagian pipa yang berisi fluida air di bagian atas.

\section{METODOLOGI}

Penelitian pemanfaatan panas dengan evacuated tube collector ini dibagi menjadi beberapa tahap, yaitu pembuatan gambar perencanaan alat, penentuan bahan dan alat, pembuatan alat, pengujian alat dan analisis data.

Solar water heater ini dibuat menggunakan beberapa material, yaitu pipa tembaga, tabung kaca, absorber dan komponen lainnya.

Pelat absorber dibuat dari bahan aluminium yang dicat hitam, pipa inlet dan outlet saluran air dari bahan pipa tembaga, dan rangka solar water heater dari bahan besi siku.

Selanjutnya dilengkapi dengan pemasangan komponen elektronika sebagai alat sensor atau alat ukur, dan penempatan pelat absorber ke pipa tembaga etanol. Kemudian dipasangkan tabung kaca yang divakumkan sebesar -0.95 barg.

Pengujian alat dilakukan pada pukul 09.0015.00 pada keadaan cuaca cerah. Pada saat itu diharapkan intenstas cahaya matahari dapat diperoleh semaksimal mungkin.

Untuk tahap analisis data, digunakan persamaan (1).

$$
\eta=\frac{m \times C_{p} \times\left(T_{f o}-T_{f i}\right)}{A_{k} \times I_{g}}
$$

\section{HASIL DAN PEMBAHASAN}

Data pengujian sebanyak 16 data diambil dari pukul 10.00-13.45 dengan rentang 15 menit setiap pengambilan data, dan debit air yang dipanaskan sebesar $5 \mathrm{ml} /$ detik. Data yang diperoleh dapat dilihat pada Tabel 1.

Tabel 1. Data Pengujian Kolektor Surya

\begin{tabular}{|c|c|c|c|c|c|c|}
\hline \multirow{3}{*}{ No } & \multirow[t]{2}{*}{ Waktu } & \multicolumn{2}{|c|}{$\begin{array}{l}\text { Intensitas } \\
\text { Matahari }\end{array}$} & \multirow{2}{*}{\multicolumn{2}{|c|}{$\begin{array}{c}\begin{array}{c}\text { Temperatur } \\
\left({ }^{\circ} \mathrm{C}\right)\end{array} \\
\text { air }\end{array}$}} & \multirow{3}{*}{ Ket } \\
\hline & & \multirow{2}{*}{$\frac{I}{W / m^{2}}$} & \multirow{2}{*}{\begin{tabular}{|c|} 
Ik \\
kWh'm ${ }^{2}$ \\
\end{tabular}} & & & \\
\hline & $t$ & & & in & ouf & \\
\hline 1 & 10.00 & 648 & 0 & 27 & 29.5 & Cerah \\
\hline 2 & 10.15 & 630 & 0.16 & 27.4 & 29.6 & Cerah \\
\hline 3 & 10.30 & 681 & 0.33 & 27.8 & 30.2 & Cerah \\
\hline 4 & 10.45 & 701 & 0.50 & 28.3 & 309 & Cerah \\
\hline 5 & 11.00 & 742 & 0.69 & 28.7 & 31.6 & Cerah \\
\hline 6 & 11.15 & 656 & 0.85 & 29.4 & 31.7 & Cerah \\
\hline 7 & 11.30 & 560 & 0.99 & 29.8 & 31.1 & Berawan \\
\hline 8 & 11.45 & 677 & 1.16 & 30.2 & 32.5 & Cerah \\
\hline 9 & 12.00 & 688 & 1.33 & 30.5 & 32.7 & Cerah \\
\hline 10 & 12.15 & 604 & 1.48 & 30.9 & 32.7 & Cerah \\
\hline 11 & 1230 & 612 & 1.64 & 31.4 & 33.3 & Cerah \\
\hline 12 & 12.45 & 608 & 1.79 & 31.8 & 33.4 & Cerah \\
\hline 13 & 13.00 & 600 & 1.94 & 32.3 & 33.9 & Cerah \\
\hline 14 & 13.15 & 610 & 2.09 & 32.9 & 34.5 & Cerah \\
\hline 15 & 13.30 & 588 & 2.24 & 32.8 & 34.7 & Berawan \\
\hline 16 & 13.45 & 590 & 239 & 33.6 & 35.4 & Berawan \\
\hline
\end{tabular}

Data hasil perhitungan dapat diplotkan ke dalam grafik yang disajikan pada Gambar 1 hingga Gambar 4. 


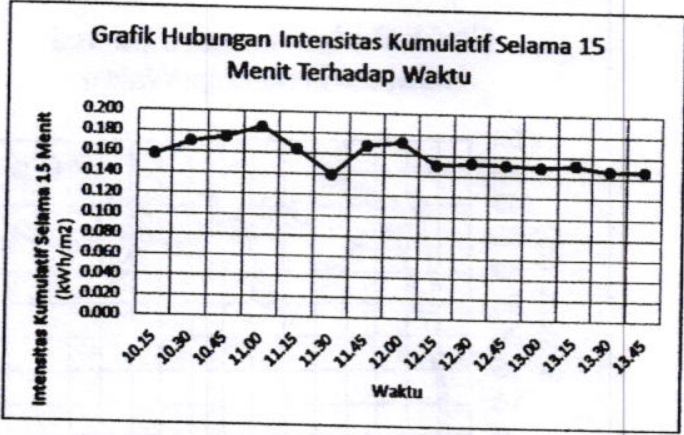

Gambar 1. Hubungan Intensitas Kumulatif Selama 15 Menit Terhadap Waktu

Gambar 1 menunjukan bahwa hubungan intensitas kumulatif selama 15 menit pemanasan terhadap waktu. Intensitas kumulatif matahari selama 15 menit mengalami nilai yang fluktuatif. Hal ini disebabkan oleh kondisi cuaca yang berubah-ubah sehingga mempengaruhi nilai intensitas matahari kumulatif selama 15 menit.

Nilai intensitas kumulatif matahari terkecil yaitu pada saat pukul 11.30 sebesar 0,140 $\mathrm{kWh} / \mathrm{m}^{2}$. Hal ini dipengaruhi oleh kondisi langit yang terhalang gumpalan awan.

Nilai intensitas kumulatif matahari terbesar berada pada saat pukul 11.00 sebesar 0,186 $\mathrm{kWh} / \mathrm{m}^{2}$. Hal ini disebabkan pada saat itu intensitas pancaran matahari sangat tinggi.

Akan tetapi dari pukul 12.15-13.45 nilai intensitas kumulatif matahari relatif kecil karena terjadinya pergeseran posisi matahari ke posisi terbenam.

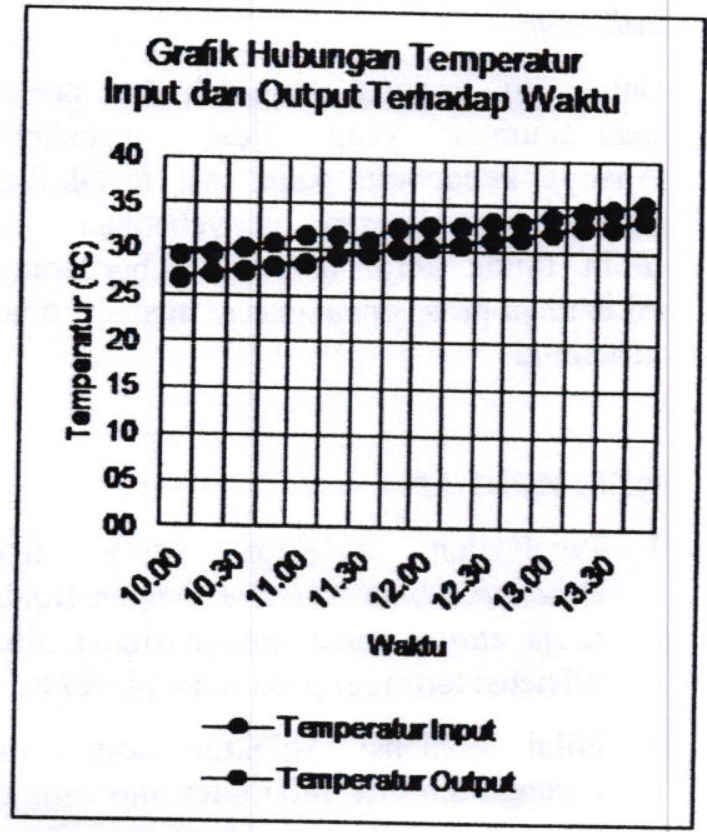

\section{Gambar 2. Hubungan Temperatur Masuk dan Keluar Air Terhadap Waktu}

Pada Gambar 2 dapat dilihat hubungan temperatur air masuk dan keluar terhadap waktu pengujian. Nilai temperatur air keluar yang dihasilkan oleh proses pemanasan di dalam kolektor meningkat sepanjang waktu. Hal ini dikarenakan adanya penyimpanan panas yang cukup baik di dalam kolektor tersebut yang merupakan dampak dari efek rumah kaca yang merupakan suatu prinsip kerja dari kolektor surya tersebut, sehingga temperatur air keluar menjadi panas, walaupun intensitas radiasi matahari mengalami penurunan.

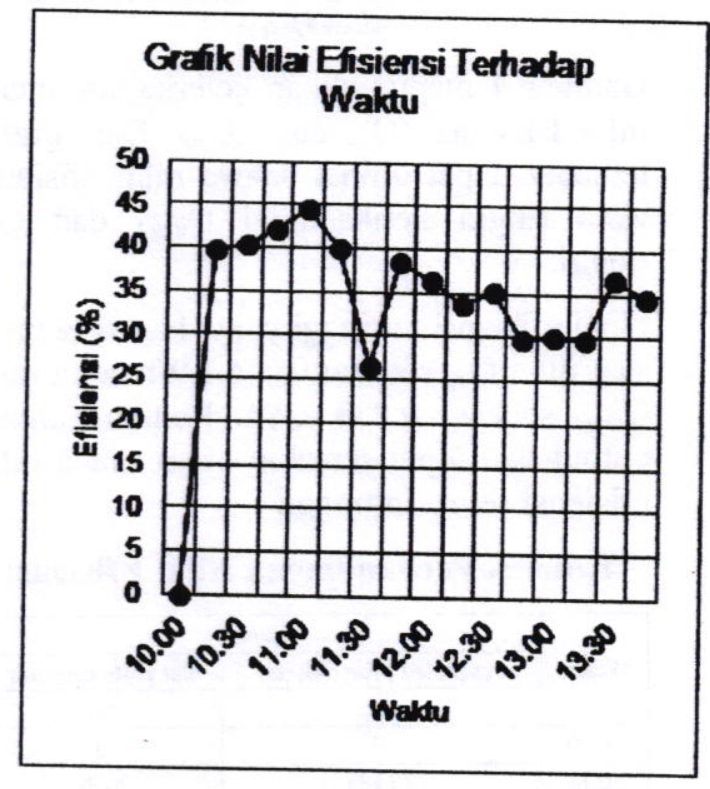

\section{Gambar 3. Nilai Efisiensi}

Gambar 3 menunjukan nilai hubungan antara nilai efisiensi terhadap waktu pengujian kolektor surya. Nilai efisiensi kolektor surya dipengaruhi oleh nilai temperatur air masuk dan keluar kolektor serta nilai intensitas radiasi matahari kumulatif yang diterima oleh kolektor surya tersebut.

Pemilihan bahan untuk media penangkap matahari pun perlu diperhatikan. Bahan dengan jenis tembaga dipilih karena memiliki nilai konduktivitas termal yang baik dan mampu menjaga panas dari matahari. 


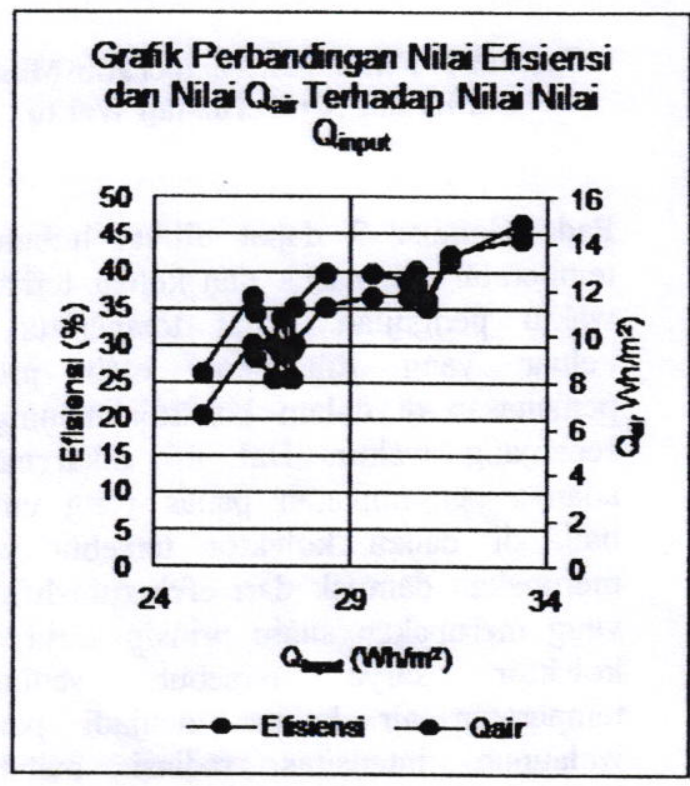

Gambar 4. Hubungan Nilai Efisiensi, $Q_{\text {air }}$ dan $Q_{\text {input }}$

Gambar 4 menunjukkan keterkaitan antara nilai Efisiensi, Qair dan $Q_{\text {input. Dari grafik }}$ tersebut dapat dilihat bahwa nilai efisiensi akan tinggi ketika nilai Q input dan Qair tinggi.

Nilai efisiensi tertinggi yaitu $44,497 \%$ pada saat nilai $Q_{\text {air }}$ sebesar $0,015 \mathrm{kWh}$ serta nilai Qinput sebesar $0,033 \mathrm{kWh}$. Rentang antara output dan input semakin besar maka nilai efisiensi semakin tinggi.

Tabel 3. Perbandingan Nilai Efisiensi

\begin{tabular}{|c|c|c|}
\hline \multirow{2}{*}{ Waldu } & \multicolumn{2}{|c|}{ Efisiensi } \\
\cline { 2 - 3 } & evacuated tube collector & flat plate collector \\
\cline { 2 - 3 } & $\%$ & $\%$ \\
\hline 10.00 & 0 & 0 \\
\hline 10.15 & 39.843 & 24.84 \\
\hline 10.30 & 40.184 & 36.36 \\
\hline 10.45 & 42.258 & 34.86 \\
\hline 11.00 & 44.497 & 29.4 \\
\hline 11.15 & 39.896 & 37.61 \\
\hline 11.30 & 26.419 & 40.09 \\
\hline 11.45 & 38.617 & 36.96 \\
\hline 12.00 & 36.335 & 42.43 \\
\hline 12.15 & 33.854 & 42.68 \\
\hline 12.30 & 35.241 & 40.8 \\
\hline 12.45 & 29.862 & 41.71 \\
\hline 13.00 & 30.239 & 46.52 \\
\hline 13.15 & 29.719 & 46.26 \\
\hline 13.30 & 36.609 & 45.73 \\
\hline 13.45 & 34.528 & 45.22 \\
\hline
\end{tabular}

(Sumber: Candarasmi, 2013)

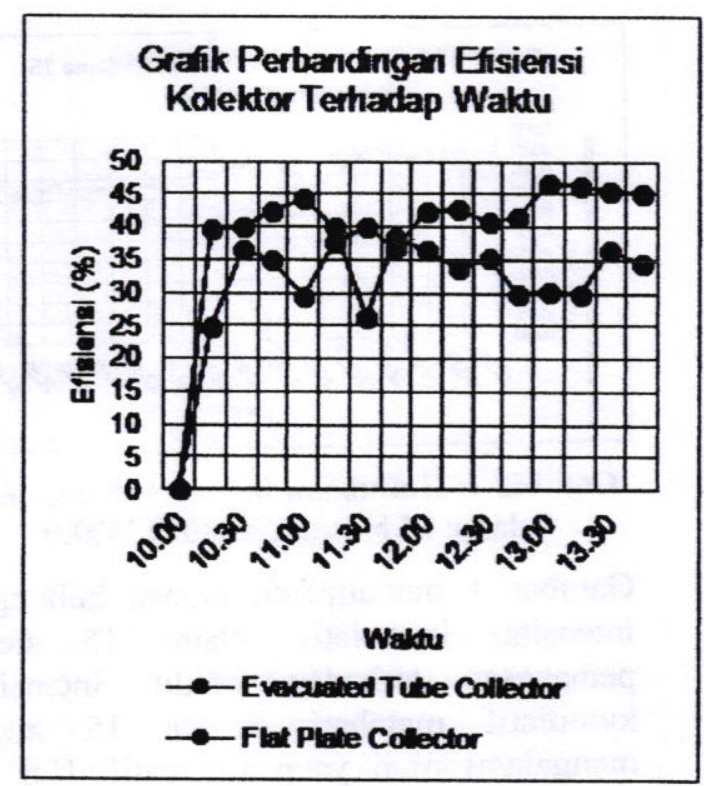

Gambar 5. Perbandingan Kinerja

Gambar 5 menunjukan perbandingan kinerja dari dua jenis kolektor surya, yaitu tipe evacuated tube collector dan flat plate collector. Pengujian masing-masing alat dilakukan pada saat interval waktu pengujian yang sama. Kinerja paling baik diperlihatkan oleh flat plate collector dibandingkan dengan evacuated tube collector. Hal ini disebabkan luasan absorber pada evacuated tube collector sangat kecil $\left(0,18 \mathrm{~m}^{2}\right)$ jika dibandingkan dengan luasan absorber pada flat plate collector $\left(0,63 \mathrm{~m}^{2}\right)$. Oleh karena itu nilai Qinput yang diterima oleh pelat absorber pada evacuated tube collector lebih kecil jika dibandingkan dengan flat plate collector.

Selain itu, terdapat pengaruh dari proses pemvakuman yang tidak maksimal. Adanya kebocoran pada saat melakukan proses pemvakuman menyebabkan titik didih fluida kerja tidak bisa berkurang. Akibatnya proses pemanasan menjadi tidak maksimal.

\section{KESIMPULAN}

1. Pembuatan kolektor surya tipe evacuated tube collector dengan fluida kerja etanol dapat menghasilkan nilai efisiensi tertinggi pada nilai $44,497 \%$.

2. Nilai efisiensi kolektor surya ini dipengaruhi oleh nilai intensitas cahaya 
matahari serta temperatur air yang dialirkan ke dalam sistem.

3. Temperatur air keluar kolektor surya tertinggi pada nilai $35.4^{\circ} \mathrm{C}$.

\section{DAFTAR PUSTAKA}

1. Candarasmi, Mita. 2013. Pembuatan dan Pengujian pemanas Air Tenaga Surya dengan Absorber Zigzag Tanpa Pipa Sirkulasi. Jurusan Teknik Konversi Energi, Politeknik Negeri Bandung, Bandung.

2. Maridjo. 1995. Petunjuk Praktikum Mesin Konversi. Bandung: P3P.

3. Holman, J.P. 1988. "Perpindahan Kalor"(diindonesiakan oleh Ir. E. Jasifi M. Sc), Erlangga, Jakarta. 